Revista de Derecho

\title{
Una mirada interpretativa y constitucional de los derechos sociales: la reducción de las pensiones jubilares
}

\author{
A constitutional interpretative view of social rights: \\ the reduction of the retirement pensions \\ Carla Verónica Espinosa Cueva \\ Investigadora independiente \\ Ecuador \\ kespinosac@yahoo.es \\ ORCID: 0000-0001-9553-3106
}

DOI: https://doi.org/10.32719/26312484.2021.35.6

Fecha de recepción: 26 de junio de 2020

Fecha de aceptación: 22 de septiembre de 2020

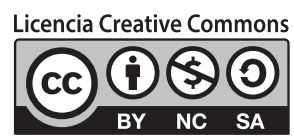




\section{RESUMEN}

Este artículo analiza la problemática de la reducción de las pensiones jubilares desde la perspectiva constitucional crítica del Estado democrático y garantista, que incluye interpretaciones dialógicas razonables, que tienen como objetivo asegurar a los jubilados la satisfacción real de sus derechos dentro del aparato burocrático y judicial, que debe concretarlos en la práctica. Lo contrario conduce a la regresividad normativa y jurisprudencial sobre la base de un discurso de ocultamiento de los principios y valores del sistema. Para ello, esta investigación se desarrolla en tres secciones. Las dos primeras partes abordan desde la teoría y la práctica los derechos sociales, seguridad social y jubilación como objeto de conocimiento y su coherencia reflexiva. Para ello, se utilizan los métodos interpretativo hermenéutico y hermenéutico lógico. La tercera, a su vez, realiza un análisis teórico sistémico de la problemática de la disminución de las pensiones del que se infiere que cualquier medida regresiva de este derecho requiere una justificación razonable; caso contrario, es objetable constitucionalmente. En resumen, el correcto funcionamiento de las instituciones a través de lecturas progresivas de las normas, principios y políticas públicas en pro de los derechos sociales legitima el discurso de bienestar general de la sociedad.

PALABRAS CLAVE: pensión jubilar, progresividad, regresividad, razonabilidad, derechos sociales, seguridad social.

\section{ABSTRACT}

This article analyzes the problematic of the reduction of the retirement pensions from the critical constitutional perspective of the democratic and guarantee-based State, which includes reasonable dialogical interpretations that possess the main objective to reassure the retirees the real satisfaction of their rights within the bureaucratic and judicial apparatus, which must be specified in the practice. On the contrary, this brings a regressivity on the normative and the jurisprudential activity. For that, this investigation is developed in three different sections. The first two sections, acknowledged from the theory and the practice of social rights, social security and retirement as an object of knowledge and reflexive coherence. For that, the following methods will be usage: the hermeneutic interpretative method and hermeneutic logical method. The third performs a systematic theoretical analysis of the problem of the decreasing element of the pensions, from which can be inferred that any regressive measure of this rights requires a reasonable justification; otherwise, it is constitutionally objectionable. In conclusion, the correct functioning and operation of the institutions through progressive lectures of the norms, principles and public politics that are pro of social rights, legitimate the general well-being lecture of society.

KEYWORDS: retirement pension, progressivity, regressivity, reasonableness, social rights, social security. 


\section{INTRODUCCIÓN}

E ste artículo analiza, desde una perspectiva constitucional, la cuestión de la reducción de las pensiones jubilares y ciertos problemas de interpretación técnicopolíticos que plantean este tipo de derechos sociales en espacios de globalización capitalista, con el fin de lograr un cierto activismo judicial que busque la efectiva garantía estatal.

La alternativa interpretativa la jubilación como un derecho que promueve el bienestar social de las personas y las trata desde su integralidad e interdependencia, valora sus necesidades materiales y económicas y procura condiciones de dignidad que permitan a los adultos mayores alcanzar una vida plena. Esto significa que el Estado debe desarrollar políticas o medidas de acción positiva que permitan mejorar la satisfacción de las necesidades básicas y la protección y garantía a sus derechos.

El buen vivir propugna la deconstrucción de la doctrina neoliberal burguesa que tiene como fundamento inmediato la libertad individual y propiedad privada propios de los derechos civiles y políticos y, en su lugar, promueve la solidaridad social a la que se encuentran conectados los derechos sociales y sus correspondientes tesis en el discurso jurídico, pero entendidos como derechos iguales, interdependientes y de igual jerarquía.

Esta lectura alternativa desde el constitucionalismo actual permite ampliar el catálogo de los derechos con el fin de asegurar a los jubilados la satisfacción real de sus necesidades básicas y, con ello, el goce de su libertad.

Además, esta lectura posibilita inscribir la jubilación como un derecho constitucional, en un proceso de constante democratización frente a los reclamos sociales de este grupo de atención prioritaria. Con ello se articulan de mejor manera las garantías y la democracia en aras de remover los obstáculos materiales que explican su posición debilitada en la mayoría de ordenamientos actuales. ${ }^{1}$ Para este propósito se estudia el principio de no regresividad y de realización mínima de los derechos sociales.

Sin embargo, resulta imposible desconocer, como señala Sustein y Holmes, que tanto las libertades negativas como los derechos sociales (libertades positivas) cuestan dinero, es decir, requieren de permanente inversión estatal. ${ }^{2}$ Por ello, es necesario la razonabilidad de medidas regresivas.

1. Gerardo Pisarello, Los derechos sociales y sus garantías. Elementos para una reconstrucción (Madrid: Trota, 2007), 17-8.

2. Rodolfo Arango señala que, si bien hay algunos derechos que representan mayores costos económicos que el de otros, no obstante, tanto las libertades positivas como negativas son correlativas, por lo que al momento de garantizarlos no hay una diferencia estructural entre ellos. Cfr. Rodolfo Arango, El concepto 
Por ello, la pregunta central reconduce a un análisis serio de la jubilación dentro del constitucionalismo crítico, que se construya desde la problemática política contextual de los derechos sociales con el fin de asegurar el afianzamiento democrático a través de controles efectivos que posibiliten su vigencia y respaldo judicial por medio del aparato burocrático que debe concretarlas en la práctica. ${ }^{3}$

El reconocimiento efectivo de la jubilación depende de una tarea compleja de planificación, previsión presupuestaria, gestión de los sistemas de seguridad social y regulación concreta de las relaciones laborales de los poderes políticos de turno que contrarreste a las fuerzas dominantes de legitimación neutral del discurso técnico-jurídico.

Por tanto, el objetivo general de este artículo es demostrar que, a partir de interpretaciones razonables de carácter progresivo y no regresivo de la jubilación, como el in dubio pro justicia sociales, que incluyan discursos dialógicos y teleológicos de transformación social, es posible garantizar lecturas más garantistas que estén de conformidad con la Constitución y el principio democrático. Lo contrario conduce a la regresividad normativa o jurisprudencial sobre la base de una dialéctica de ocultamiento u opacidad de los principios y valores del sistema para justificar la inacción estatal.

Para cumplir con dicho objetivo, este artículo, en las dos primeras secciones, utiliza como métodos de investigación el interpretativo hermenéutico y hermenéutico lógico, pues existe un interés conceptual y práctico por comprender y problematizar la jubilación como objeto de conocimiento y su coherencia discursiva desde la doctrina y la jurisprudencia. Pero, a la vez, la tercera parte realiza un análisis teórico sistémico de la problemática de la disminución de la pensión jubilar, en el que se concluye que toda medida regresiva de derechos requiere una justificación razonable; ${ }^{4}$ en caso contrario, es inconstitucional.

de derechos sociales fundamentales (Bogotá: Legis, 2005). Por su parte, Paul Hunt, relator especial de la Comisión de Derechos Humanos de Naciones Unidas sobre el Derecho a la Salud, distingue entre indicadores estructurales, de proceso y evolución. Los indicadores estructurales permiten evaluar la progresividad o regresividad normativa y los indicadores de proceso y evolución permiten evaluar la progresividad y regresividad de los resultados de una política pública. Informe Provisional del Relator Especial de la Comisión de Derechos Humanos sobre el derecho de toda persona al disfrute del más alto nivel posible de salud física y mental, A/58/427, 10 de octubre de 2003, párrafos 5-37. Todo ello permitiría inferir que el sistema de Naciones Unidas sí establece estándares estructurales con relación a los derechos económicos, sociales y culturales. Cfr. Christian Courtis, "La prohibición de regresividad en materia de derechos sociales: apuntes introductorios", en Ni un paso atrás: la prohibición de regresividad en materia de derechos sociales, comp. Christian Courtis (Buenos Aires: Del Puerto, 2006), 3 y ss.

3. Lo contrario lleva a una regresividad de los resultados de una política pública (regresividad de resultados). Cfr. Courtis, ibíd., 3 y ss.

4. El término razonable alude a una visión no solo lógica formal, sino que incluye un análisis argumentativo discrecional de un conjunto de razones materiales multifactoriales reales vigentes en un determinado contexto y espacial en una dinámica de saberes políticos, culturales y económicos, que requieren de un 
El artículo se desarrolla en tres partes. La primera aborda la problemática actual de los derechos sociales. La segunda aborda el concepto, revisión crítica de la seguridad social con relación a otros derechos y su jurisprudencia relevante. La tercera analiza, desde una perspectiva crítico-constitucional, el problema de la disminución de las pensiones jubilares y se plantean algunas estrategias argumentales para la realización de este derecho.

\section{LA PROBLEMÁTICA ACTUAL DE LOS DERECHOS SOCIALES}

Con la crisis del Estado social y la restauración del capitalismo globalizado ${ }^{5}$ existe un progresivo vaciamiento normativo de los derechos sociales - protección debilitada - y la reivindicación de los derechos de propiedad y libre mercado, que parten de un discurso artificial de negación del conflicto que erosiona los elementos garantistas e igualitarios del Estado constitucional hacia un modelo librecambista y de acumulación de capital.

Ello obedece, en parte, a ciertos dogmas que corresponden con cuatro tesis diferentes del debate jurídico-político, que son: histórica, normativa, estructural y dogmática jurídica. La primera señala que los derechos sociales son de segunda o tercera generación posteriores a los civiles y políticos (primera generación). ${ }^{6}$ La clasificación normativa (filosofía de los derechos) establece que el fundamento inmediato de los derechos civiles y políticos es el principio de dignidad de la persona. En cambio, los segundos solo se ligan — de manera indirecta — a ese valor, lo que justifica su débil tutela. Esta tesis axiológica admite la formulación complementaria que establece que los derechos civiles y políticos se relacionan con la libertad y contribuyen a preservar la seguridad personal y diversidad de una sociedad. Los otros, por el contrario, se conectan al principio de igualdad y buscan la protección de la homogeneidad social. ${ }^{7}$

La noción estructural adiciona que estos son prestacionales, caros, indeterminados y de incidencia colectiva, lo que dificulta su tutela. Por último, la ponencia dogmática señala que, si se entienden los derechos sociales como secundarios (plano axiológico)

mínimo consenso de legitimidad. Aquellos argumentos no parten — necesariamente - de normas expresas, sino que se construyen y se avalan desde la praxis discusiva del derecho.

5. En una primera fase los derechos sociales surgen de la "cuestión social", a mediados del siglo XIX, como una reacción al capitalismo que alentaba el carácter absoluto de los derechos patrimoniales. Cfr. Víctor Abramovich, María José Añón y Christian Courtis, "Apuntes sobre la exigibilidad judicial de los derechos sociales", en Derechos Sociales: instrucciones de uso (Ciudad de México: Fontamara, 2003), 24.

6. Pisarello, Los derechos sociales y sus garantías, 15.

7. Ibíd. 
y presentan una estructura diferenciada de los derechos civiles y políticos (plano teórico), es lógico que gocen de una protección menor. ${ }^{8}$

Es decir, de conformidad con las doctrinas clásicas, los derechos sociales carecen desde lo constitucional de igual jerarquía que otros judicialmente exigibles, y son simples principios programáticos cuya operatividad se supedita a la libre configuración del legislador y a la aplicación residual del juzgador de turno. ${ }^{9}$

Este constitucionalismo de la crisis — ideología liberal - parte de un modelo político-económico que se desarticula de la realidad y presiona por el desmonte de las garantías sociales en un afán de homogenización del mercado laboral y la seguridad social sobre la base de un sistema de producción jurídica que refrenda las prácticas estatales de legitimación del poder.

En Latinoamérica los derechos sociales presentan dificultades adicionales relacionadas con la dependencia económica, incipiente industrialización, desigualdades de negociación comercial frente a potencias extranjeras y efectos negativos de las políticas económicas neoliberales en la población más pobre, que se traducen en retrocesos en el nivel de desarrollo de la región. Estos elementos ponen en duda las posibilidades reales de universalizar su goce y disfrute. A lo anterior se agregan las asimetrías económicas, político-institucionales y culturales que llevan implícitas barreras conceptuales, ideológicas y presupuestales. ${ }^{10}$

Este relato continuo de ausencia de Constitución y de opacidad del capitalismo invita a impulsar procesos de cambio político constitucionales que problematicen los discursos formales de negación continua de los derechos sociales bajo mecánicas de adoctrinamiento legal programadas y de aceptación automatizada de lo existente, hacia nuevas dogmáticas de entendimiento real y realización mínima de estos, en contextos de pluralismo y participación conflictuales que se adecuen y potencien los contenidos valorativos del Estado garantista. ${ }^{11}$

En entornos de desigualdad y exclusión es necesario potenciar el debate y la decisión en materia de derechos sociales, desde una perspectiva axiológica, dinámica y compleja de articulación sociopolítica, jurídica y multicultural de la Constitución

\footnotetext{
8. Ibíd.

9. Con todo, estos postulados olvidan el corpus de una serie de principios que gozan de consenso universal dentro de la comunidad internacional como la Declaración de Viena.

10. Cfr. Rodolfo Arango, "Los derechos sociales en Iberoamérica: Estado de la cuestión y perspectivas de futuro", en Dereitos Humanos, Democracia e Integração Jurídica na América do Sul, coords. von Bognandy Armin, Flavia Piovesan y M. Morales Antoniazzi (Río de Janeiro: Lumen Juris, 2010), 379-96.

11. Cfr. Carlos de Cabo Martín, Pensamiento crítico, constitucionalismo crítico (Madrid: Trotta, 2014), 73-8 y 91-5.
} 
hacia la recuperación de los valores y garantías de las personas dentro de una lógica estatal democrática.

Ello implica una apuesta hacia un constitucionalismo más reflexivo y crítico que parta desde las bases y que tome en cuenta las dinámicas reales de desarrollo, ejecución y examen de las políticas públicas en materia de derechos sociales y los desarrollos de la doctrina y la jurisprudencia nacionales e internacionales.

Junto con el reforzamiento de los mecanismos judiciales para proteger los derechos sociales es preciso avanzar en un proceso de conciencia moral, judicialización de los derechos y activismo político para su efectiva realización. ${ }^{12}$

En muchos casos, ello no requiere buscar otro sentido al derecho sino el contenido "correcto" de acuerdo con la realidad jurídica en la que opere. Las Constituciones actuales apuestan por elementos que permitan alcanzar objetivos transformadores frente a la apariencia del derecho capitalista. Esto significa que las categorías y valores constitucionales deben analizar no solo las innovaciones de las nuevas prácticas de los conflictos y movimientos sociales, sino también las destrezas innovadoras del capital. ${ }^{13}$ Es decir, es necesario la construcción de un nuevo derecho alternativo plural y local que construya y deconstruya las lecturas simbólicas o interpretaciones lingüísticas, jurídicas, sociales, políticas o económicas a fin de que sean más razonables y garantistas.

La Corte Constitucional ecuatoriana ${ }^{14}$ define los derechos sociales como derechos prestacionales suministrados por el Estado, que surgen como formas de protección a los trabajadores y obreros, frente a los infortunios derivados del trabajo, de forma que no se permita el detrimento de la dignidad humana. Y concluye, sobre la base del pensamiento de Alexy, que se regulan constitucionalmente como mandatos de optimización, ya que regulan la necesidad de alcanzar ciertos fines, pero dejan abiertas las vías para lograrlos.

Es decir, según este tribunal, los derechos sociales son mandatos de optimización que deben realizarse en la mayor medida de lo posible, en este caso, obligaciones estatales prestacionales, en forma de bienes o servicios, que deben garantizarse a través de políticas públicas y resoluciones jurisdiccionales con el fin de precautelar el bienestar individual.

12. Cfr. Arango, "Los derechos sociales en Iberoamérica", 379-90.

13. Cfr. De Cabo Martín, Pensamiento crítico, constitucionalismo crítico, 73-8.

14. Ecuador, Corte Constitucional, "Dictamen 005-13-DTI-CC", Caso 0028-11-TI, 5 de marzo de 2013. 


\section{LA SEGURIDAD SOCIAL EN EL CONTEXTO ECUATORIANO Y SU RELACIÓN CON LOS DERECHOS SOCIALES}

Queda señalado que los derechos sociales buscan el bienestar social de las personas, en especial de los grupos vulnerables frente al poder, y se sustenta en la dignidad humana y mejora de las condiciones mínimas para su realización efectiva. En este contexto, se examina la seguridad social, para luego centrarse en la jubilación.

Existe cierto consenso que define a la seguridad en los siguientes términos: (a) acción o intervención del Estado, (b) con base en la Constitución o la ley, (c) que busca proteger a los individuos de riesgos, necesidades o contingencias, (d) que provoquen consecuencias dañosas para toda la sociedad en la eventualidad de que ocurran. ${ }^{15}$

Una lectura más detallada de este tema necesita - al menos - tomar en cuenta dos aspectos: el primero, relacionado con las concepciones de la seguridad social; y, (2) el segundo, que complejiza la diferencia entre la cobertura constitucional-legal y la cobertura real. ${ }^{16}$

Existen dos criterios que deben regir la interpretación de las cláusulas constitucionales sobre seguridad social. Por un lado, la postura programática — predominante en el siglo XX - considera este derecho como parte del sistema del empleo asalariado y lo conecta con el principio contributivo. Esta perspectiva, en la actualidad, resulta cuestionable, por lo siguiente: (a) el texto constitucional (art. 3.1 de la Constitución) reconoce la seguridad social con independencia de otros derechos laborales; (2) el enfoque de igual jerarquía e interdependencia de todos los derechos; (3) el reconocimiento de los problemas sociales estructurales que aquejan a las sociedades latinoamericanas, acentuadas por las políticas neoliberales. ${ }^{17}$

La segunda, con un enfoque más evolutivo de derechos en cuanto al acceso y exigibilidad de un piso mínimo, no negociable en materia de seguridad social. Conforme con esta interpretación, se considera que los deberes impuestos al Estado por la Constitución no pueden examinarse de manera aislada y discrecional, sino a partir de una justificación armónica e integral de los derechos y principios establecidos en la Norma Suprema o en otros instrumentos internacionales de derechos humanos reco-

15. Cfr. Laura Pautassi, Legislación previsional y equidad de género en América Latina (Santiago de Chile: CEPAL-ECLAC, 2002), 11-2.

16. Cfr. Martín Aldao y Laura Clérico, "Los derechos previsionales y la seguridad social", en La Constitución en 2020. 48 propuestas para una sociedad igualitaria, coord. Roberto Gargarella (Buenos Aires: Siglo XXI, 2011), 171-7.

17. Ibíd. 
nocidos por el Estado ${ }^{18}$ con el fin de lograr, de forma progresiva, la plena efectividad de los derechos. Es decir, tanto los sistemas nacionales como el interamericano - de manera más cautelosa - se esfuerzan por desarrollar ciertas condiciones de avance en el desarrollo directo de estos derechos sociales. ${ }^{19}$

En definitiva, queda claro que se considera la seguridad social como un derecho social inalienable, irrenunciable, indivisible, interdependiente, de igual jerarquía, justiciable, que tiene el carácter de previsional y prestacional, cuyo fundamento es satisfacer las condiciones mínimas para el mejoramiento de la calidad de vida de las personas y la dignidad humana frente a infortunios futuros de naturaleza laboral, productiva y familiar, en especial, de la clase trabajadora. Para ello, se garantiza la protección de salud, las pensiones jubilares y el desempleo, así como también prestaciones sociales que se financian mediante aportes en un sistema integrado para estos fines como una forma de reivindicación de los derechos de los trabajadores. ${ }^{20}$

En cuanto a la diferencia entre cobertura legal y real, la Constitución debe interpretarse como un compromiso entre iguales del desarrollo de su proyecto de vida y de paridad participativa en la deliberación democrática. Por ello, todos sus desarrollos normativos deben adecuarse a lo dispuesto en el art. 11 de la Norma Suprema, esto es, sus contenidos deben ser interdependientes, de directa e inmediata aplicación donde es indudable la obligación del Estado de hacerlos justiciables mediante un desarrollo progresivo y de no regresión arbitraria, entre otros.

No en vano, Haberle señala que la intensificación de las prestaciones estatales, como la seguridad social y, en concreto, la jubilación, que demandan todas ellas pequeñas libertades, son, sin embargo, condiciones sine qua non para la realización de las grandes libertades políticas constitucionales.

Con relación a la jubilación, es necesario establecer: (a) el rol que juega el Estado en la provisión de este derecho; y (b) el alcance de este sistema. Con respecto al primer tema, vale advertir que las reformas institucionales y normativas relativas al derecho de la seguridad social en materia previsional contenido en el art. 37, núm. 3

18. Si bien el sistema interamericano posee múltiples formas de promocionar y proteger los Desc, aún sus avances jurisprudenciales son escasos e incipientes. Ello impide su máxima protección pese a poseer normativa jurídica internacional que los respalda como la Carta de la OEA, la Convención ADH y el Protocolo de San Salvador.

19. Cfr. Corte IDH, "Sentencia de 19 de noviembre de 1999 (Fondo)", Caso Villagrán Morales y otros vs. Guatemala (Niños de la calle), 19 de noviembre de 2010, párr. 120, https://www.corteidh.or.cr/docs/casos/articulos/Seriec_63_esp.pdf; y "Sentencia de 2 de febrero de 2001 (Fondo, Reparaciones y Costas)", Caso Baena Ricardo y otros vs. Panamá, 23 de noviembre de 2010, párr. 156, https://bit.ly/38EcMx7.

20. David Cárdenas, "El principio de no regresividad en el derecho a la seguridad social: caso suspensión y reducción de pensiones jubilares del Banco Central del Ecuador" (tesis de maestría, UASB-E, 2018), 38-9. 
de la Constitución deben adecuarse a los principios de progresividad y no regresividad arbitraria en concordancia con los artículos 26 y 29 de la $\mathrm{CADH},{ }^{21}$ así como también al mandato constitucional de participación, garantizando la representación de los beneficiarios en la administración del sistema, de tal modo que quede protegido de los cambios de los poderes públicos de turno.

En caso contrario, los desequilibrios financieros en el sistema de pensiones jubilares y de las cuentas fiscales conllevan consecuencias nocivas en términos del derecho a gozar de una vida digna y del derecho a la igualdad. Por otra parte, se recuerda que la jubilación patronal es financiada por el patrono, dentro de los rangos y requisitos que establece el Código del Trabajo. Pero este tipo de jubilación es distinta a la tan ansiada universalización de la jubilación.

Con relación al segundo tema conviene indicar que la universalización del régimen no contributivo de pensiones admite varias respuestas conforme el bloque de constitucionalidad. Sin embargo, la baja cobertura del sistema, que se refleja en un alto grado de exclusión previsional, constituye un problema latente en la seguridad social, pues no cumple el objetivo para el que fue creado y, dado que los programas siguen una lógica de financiamiento a largo plazo, las limitaciones en la cobertura generan un pasivo social y económico de largo alcance. Por lo tanto, desde el punto de vista del gasto social, el problema de la poca cobertura puede juzgarse como un aplazamiento de la inversión social.

Por ello, una discusión inclusiva busca que en el curso del tiempo se establezcan cada vez más mecanismos para alcanzar a la mayoría de personas. En la actualidad, el sistema de pensiones tiene un pasivo actuarial que el Estado debe afrontar. Sin embargo, es necesario buscar condiciones para garantizar la factibilidad fiscal y económica a largo plazo para una universalización de la protección social en pensiones mediante opciones innovadoras de financiamiento que, por ejemplo, no solo se centren en el subsidio del gasto sino también de las contribuciones.

Por ello, la interpretación constitucional correcta impide al ente estatal omitir avanzar en la protección de la universalización de los derechos previsionales, en especial de aquellas personas que requieren de tratamiento prioritario y especializado en lo público y privado, en los campos de inclusión social y económica, así como en el acceso a la jubilación universal; asimismo, debe orientar sus acciones hacia su cum-

21. Cfr. OEA. Convención Americana de Derechos Humanos, en adelante, CADH, 7 al 22 de noviembre de 1969. Por su parte, el artículo 2.1 del Pacto Internacional de Derechos Económicos, Sociales y Culturales, en adelante PIDESC y los artículos 1, 2 y 3 del Protocolo Adicional a la Convención Americana sobre Derechos Humanos en materia de Derechos Económicos, Sociales y Culturales (Protocolo de San Salvador), contienen disposiciones relacionadas con el tema. 
plimiento adecuado y suficiente (del haber mínimo), así como brindar los mecanismos suficientes para el acceso efectivo a este derecho en caso de incumplimiento. ${ }^{22}$

El sistema previsional único para las personas constituye una medida adecuada para cumplir con el principio de igualdad y de justicia, ya que incorpora a los grupos más vulnerables de la población, con el fin de disminuir la fragmentación social, independientemente de la situación laboral. Conforme una interpretación inclusiva y progresiva del alcance del sistema previsional, no de forma contributiva, sino en pro de los derechos, es necesario que el sistema garantice una adecuada cobertura y contemple las situaciones de riesgo en los que se encuentran las mujeres, las personas con discapacidad, los trabajadores excluidos del sistema, entre otros. El Estado debe prestar especial protección a las personas en condición de doble o múltiple vulnerabilidad. ${ }^{23}$

Este criterio no resulta ajeno a lo que señalan la Corte Europea de Derechos Humanos ${ }^{24}$ la Corte Interamericana de Derechos Humanos ${ }^{25}$ y la jurisprudencia constitucional argentina ${ }^{26}$ que señalan que, en materia de derechos sociales, rige la regla hermenéutica in dubio pro justitia socialis que favorece la vigencia de la norma de derecho social de mayor alcance. En el caso de la prohibición de regresividad, se somete a escrutinio estricto la norma posterior que pretende limitar la extensión del derecho por medio de un test de razonabilidad que justifique la medida. ${ }^{27}$ En concreto, la Corte Suprema argentina señala:

Tiene categoría constitucional el siguiente principio de hermenéutica jurídica: in dubio pro justitia sociales. Las leyes, pues, deben ser interpretadas a favor de quienes al serles aplicadas con este sentido consiguen o tienden a alcanza el bienestar, esto es, las condiciones de vida mediante las cuales es posible a la persona humana desarrollarse conforme a su excelsa dignidad. [...] [Esta Corte] ha afirmado, enfáticamente, que las leyes de materia previsional deben interpretarse conforme a la finalidad que con ellas se persigue, lo que impide fundamentar una interpretación restrictiva". No solo, pues, la interpretación ana-

22. Cfr. Argentina. Corte Suprema. Caso Víctor Francisco Rolán Zapa, de 30 de octubre de 1986 quien, a través de la aplicación del principio de razonabilidad, declaró la inconstitucionalidad de una ley reglamentaria del derecho a jubilaciones móviles del art. 14 bis de la Constitución argentina, por conducir a una desproporcionada reducción de los haberes previsionales con claro apartamiento de los derechos constitucionales consagrados.

23. Cfr. Aldao y Clérico, "Los derechos previsionales y la seguridad social", 176.

24. Cfr. Corte EDH, Casos (1) Abdulaziz, Cabales y Balkandali c. Reino Unido, Sentencia de 25 de mayo de 1985 y (2) Caso Irlanda c. Reino Unido, Sentencia de 18 de enero de 1978, aunque referentes a otros derechos.

25. Corte IDH, "Sentencia de 31 de agosto de 2004 (Fondo, Reparaciones y Costas)", Caso Ricardo Canese vs. Paraguay, 31 de agosto de 2004, https://bit.ly/3iH8oC1.

26. Argentina, Corte Suprema, Caso Berçaitz, Miguel Ángel s/jubilación, 13 de septiembre de 1974.

27. Cfr. Courtis, "La prohibición de regresividad en materia de derechos sociales: apuntes introductorios", 41. 
lógica restrictiva de un derecho social — en el caso, previsional- contraría a la uniforme jurisprudencia de esta Corte, concordante con la doctrina universal (el principio de favorabilidad), Günstigkeitprinzip, que formularon los autores alemanes a partir de la Constitución de Weimar [...], sino que también se contrapone a la hermenéutica de las leyes que surge [...] del objetivo preeminente de promover el bienestar general que la Constitución se propone obtener para todos los habitantes del suelo argentino. ${ }^{28}$

En conclusión, conforme con la doctrina y jurisprudencia, el contenido esencial del derecho a la seguridad social debe asegurar a toda persona una protección contra las consecuencias de la vejez o de cualquier otra contingencia ajena a su voluntad que implique una privación de los medios de subsistencias imprescindibles, para que pueda llevar una vida decorosa y digna.

\section{ANÁLISIS CRÍTICO-CONSTITUCIONAL SOBRE LA PROBLEMÁTICA DE DISMINUCIÓN DE LA PENSIÓN JUBILAR Y ESTRATEGIAS ARGUMENTALES PARA SU REALIZACIÓN}

Queda indicado que tanto la Constitución como la jurisprudencia reconocen y protegen la pensión jubilar como un derecho social que deben garantizarse - en la mayor medida de lo posible - por parte del Estado, con el fin de satisfacer necesidades individuales básicas.

Por su parte, el Pacto Internacional de Derechos Económicos, Sociales y Culturales $^{29}$ define el contenido mínimo esencial de cada derecho, entre ellos, la jubilación. Por ello, es obligación estatal el asegurar el cumplimiento de estas necesidades previstas en este instrumento internacional a las personas y grupos que no están en condiciones de asumirlas por sí mismas de forma progresiva y efectiva.

En efecto, el artículo 2.1 del Pidesc establece: "cada uno de los Estados parte en el presente Pacto se compromete a adoptar [...] medidas para lograr progresivamente, por todos los medios apropiados [...] la plena efectividad de los derechos aquí reconocidos". Esto, por un lado, envuelve el reconocimiento paulatino de los derechos, en contraste con lo dispuesto en el artículo 2 del Pacto Internacional de Derechos Civiles y Políticos, que supone una obligación contigua de respetar y asegurar todos los dere-

28. Argentina, Corte Suprema de Justicia de la Nación, Caso Berçaitz, Miguel Ángel s/jubilación, 13 de septiembre de 1974, Fallos: 437.

29. ONU, Asamblea General, Pacto Internacional de Derechos Económicos, Sociales y Culturales. Adoptado por resolución 2200 (XXI), 16 de diciembre de 1966. En delante de cita PIDESC. 
chos a los que se refiere dicha normativa. Pero, por otro, se recalca la necesidad de la obligación estatal de implementación progresiva de estos derechos.

De igual manera, el artículo 26 de la Convención Americana de Derechos Hu$\operatorname{manos}^{30}$ se refiere a la responsabilidad estatal de adoptar medidas para el desarrollo progresivo de los derechos sociales. El artículo 19 del Protocolo Adicional a la Convención Americana sobre Derechos Humanos en materia de Derechos Económicos, Sociales y Culturales ${ }^{31}$ se refiere al compromiso de los Estados de presentar informes periódicos sobre las medidas progresivas que se adopten para el resguardo de estos derechos.

A la vez, la Observación General 3 del Comité de Derechos Económicos, Sociales y Culturales señala que el hecho de que la realización sea progresiva no implica privarlo de la obligación de todo contenido significativo y adiciona que cualquier medida regresiva requiere justificarse plenamente con relación a la totalidad de los derechos previstos en el Pacto y en el contexto del aprovechamiento pleno del máximo de los recursos de que se dispone. ${ }^{32}$

En resumen, el sistema interamericano incorpora múltiples formas de promocionar y proteger los derechos sociales sobre pensiones jubilares que van desde la propia competencia de la Comisión IDH, presentación de informes y la existencia de instrumentos normativos internacionales sobre el particular.

Por su parte, las Directrices de Maastricht sobre Violaciones a los Derechos Económicos, Sociales y Culturales señalan como lesivos estos derechos, el acoger normas jurídicas o políticas incompatibles con los deberes legales preexistentes a los derechos sociales, salvo que su fin sea el mejorar, de forma progresiva, las condiciones de igualdad en su realización, incluidos de los jubilados.

Este principio se relaciona con el in dubio pro justicia sociales que establece la Corte Suprema de Justicia de la Nación argentina, relativo a la regulación e interpretación normativa más favorable al bienestar social, esto es, que se satisfagan las condiciones de vida mediante las cuales se asegure a las personas su $\operatorname{dignidad}^{33}$ y el principio pro homine.

30. ONU, Asamblea General, Convención Americana sobre Derechos Humanos, Pacto de San José, 22 de noviembre de 1969.

31. OEA, Asamblea General, Protocolo Adicional a la Convención Americana sobre Derechos Humanos en materia de derechos económicos, sociales y culturales, Protocolo de San Salvador, 17 de noviembre de 1988.

32. Cfr. Courtis, "La prohibición de regresividad", 10.

33. Argentina, Corte Suprema, Berçaitz, Miguel Ángel s.jubilación, 13 de septiembre de 1974, CSJN, Fallos 289:430. 
Vía jurisprudencial, la Corte Constitucional en la Sentencia 287-16-SEP-CC ${ }^{34}$ reconoce a la jubilación como un derecho fundamental que se garantiza a todos los trabajadores que cumplan con los requisitos previstos por la normativa laboral, luego de lo cual se constituye en un derecho adquirido y que no puede ser condicionado con posterioridad a su reconocimiento.

Por su parte, la Corte IDH en la sentencia de los "Cinco Pensionista c. Perú", relativo a la violación de la prohibición de regresividad en materia de pensiones de jubilación, señala que la variación en las condiciones de las jubilaciones no solo constituye una violación a los derechos de los trabajadores sino también a la propiedad privada.

En este caso, la Corte IDH analiza: (a) el derecho a la seguridad social como uno de los derechos derivados de las normas económicas y sociales de la Carta de la Oea; (b) el derecho a la seguridad social que incluye el derecho a percibir pensiones de jubilación o retiro; y (c) que el Estado no puede empeorar injustificadamente el nivel de goce de ese derecho, pues las limitaciones a este principio solo pueden efectuarse por leyes "que hayan sido promulgadas con el objeto de preservar el bienestar general dentro de una sociedad democrática, y que no contradigan el propósito y razón de tales derechos". ${ }^{35}$

Dicho organismo adiciona que las medidas adoptadas por el Estado peruano violan los derechos de propiedad y protección judicial. Agregan, con respecto a la fundamentación, que los jubilados tienen un derecho adquirido al pago de una pensión de cesantía bajo el régimen establecido en el Decreto Ley 20530, cuyo valor se nivela con la remuneración que perciben las personas que desempeñan similares labores a aquellas que ejercía el beneficiario de la pensión al momento de retirarse del cargo y que, el Estado viola el derecho del artículo 21 — propiedad privada — en relación con el artículo 29.b) de la CADH, al disminuir por ley en perjuicio de los pensionistas, el monto de las pensiones niveladas que percibían desde su jubilación. Esta reducción de casi el $80 \%$ violenta el derecho de propiedad. Además, la Corte señala:

116. Si bien el derecho a la pensión nivelada es un derecho adquirido, de conformidad con el artículo 21 de la Convención, los Estados pueden poner limitaciones al goce del derecho de propiedad por razones de utilidad pública o interés social. En el caso de los efectos patrimoniales de las pensiones (monto de las pensiones), los Estados pueden reducirlos únicamente por la vía legal adecuada y por los motivos ya indicados. ${ }^{36}$

34. Ecuador, Corte Constitucional, "Sentencia 287-16-SEP-CC", Caso 0578-14-EP, 31 de agosto de 2016.

35. Cfr. Courtis, "La prohibición de regresividad", 44.

36. Corte IDH, "Cinco Pensionista c. Perú”, citado por Courtis, ibíd., 3-53. 
Por último, se señala que el Estado, para imponer límites, debe: (a) realizar un procedimiento administrativo con pleno respeto a las garantías adecuadas; y (b) respetar, las decisiones que adoptan los tribunales de justicia. ${ }^{37}$

Por ello la Corte IDH concluye que el Estado, al cambiar arbitrariamente el monto de las pensiones, viola el derecho a la propiedad (artículo 21) en perjuicio de los pensionistas. Además, se violentan los artículos 25 (protección judicial), al no existir mecanismos eficaces que remedien el derecho conculcado y 26 (desarrollo progresivo) pues el Estado adopta medidas regresivas con respecto al grado de desarrollo alcanzado del derecho que no se pueden justificar en función del bienestar general de la sociedad democrática o que no contraríe el propósito y razón de tales derechos.

Si bien los argumentos de la Corte ofrecían la oportunidad de extender su examen con respecto a la lesión del derecho a propiedad hacia la justiciabilidad del artículo 26 y la prohibición de regresividad de los derechos económicos, sociales y culturales; no obstante, sus razonamientos fueron bastantes inertes, en especial, los párrafos 147 y 148, que dicen:

147. Los derechos económicos, sociales y culturales tienen una dimensión tanto individual como colectiva. Su desarrollo progresivo, [...] se debe medir, en el criterio de este Tribunal, en función de la creciente cobertura de los derechos económicos, sociales y culturales en general, y del derecho a la seguridad social y a la pensión en particular, sobre el conjunto de la población, teniendo presentes los imperativos de la equidad social, y no en función de las circunstancias de un muy limitado grupo de pensionistas no necesariamente representativos de la situación general prevaleciente.

148. Es evidente que esto último es lo que ocurre en el presente caso y por ello la Corte considera procedente desestimar la solicitud de pronunciamiento sobre el desarrollo progresivo de los derechos económicos, sociales y culturales en el Perú, en el marco de este caso. ${ }^{38}$

Estos argumentos de la Corte resultan endebles, al menos, por tres razones: (a) Al analizarse la violación al derecho a la propiedad, se emplea como criterio de interpretación el artículo 5 del Protocolo de San Salvador (párrafo 116), e integra el contenido del derecho de propiedad cuando de lo que se trata es de créditos previsionales con consideraciones relativas al propósito y razón de los Desc. Ello supone reconocer una dimensión individual justiciable al derecho a la seguridad social, por vía de su conexidad con el derecho a la propiedad, aunque reconociendo principios de interpretación propios de los Desc. Esto choca con la conclusión del párrafo 147, que parece sostener que la única forma de evaluar el cumplimiento de las obligaciones emergentes de los

37. Ibíd., párr. 117.

38. Ibíd., párr. 147 y 148. A la vez, cfr. Courtis, "La prohibición de regresividad", 3-52. 
Desc es en relación con el conjunto de la población enervando sus posibilidades de justiciabilidad. (b) La mención que hace este organismo de la doctrina del Comité de Derechos Económicos, Sociales y Culturales, en especial de las Observaciones Generales 3 relativa "La índole de las obligaciones de los Estados parte" y 9 sobre justiciabilidad de los derechos, es desafortunada, pues, si bien toma ciertos párrafos de dicha doctrina, las conclusiones son opuestas, ya que aquella señala que la noción de progresividad establecida en el Pacto de Derechos Económicos, Sociales y Culturales no riñe con la justiciabilidad de esos derechos. Algo parecido sucede con la CADH. (c) Por último, resulta sospechoso que la Corte evalúe el goce de los Desc en función del conjunto de la población, pues su competencia se circunscribe a reclamos de naturaleza individual o de grupo de personas. El reconocer la dimensión individual o colectiva de estos derechos no significa desprenderlos de su carácter de justiciables. ${ }^{39}$

En resumen, la Corte tiene dos dificultades conceptuales: (a) confunde la dimensión colectiva con la escala nacional, y (b) mantiene cierta reticencia de analizar en un caso contencioso temas vinculados con el diseño de las políticas públicas y la disposición de los recursos públicos.

A partir de aquí, se considera necesario que, dentro del análisis de la razonabilidad de las pensiones jubilares, se tome en cuenta que: (1) Se trata de un derecho adquirido autónomo y de igual gradación a otros, que requiere una realización mínima. (2) Puede interpretarse solo o dentro del conjunto de derechos de carácter previsional y prestacional de la seguridad social y de valores y principios — en general- previstos en la Constitución, según las circunstancias concretas. (3) El reconocer la dimensión individual o colectiva de estos derechos no significa segregar su carácter de justiciable. (4) Debe desarrollarse de forma progresiva sin que se lo pueda restringir o limitar su contenido sin una razón pública aceptable con respecto a ese obrar estatal. (5) La interpretación y aplicación de este derecho requiere superar las barreras conceptuales jurídico políticas impuestas desde las lógicas acríticas formales de adoctrinamiento neoliberal hacia la convergencia de otros saberes dinámicos que incluyan la realidad local conflictual. Ello incluye la creación de una doctrina propia de los derechos sociales desde las prácticas conflictuales internas del capital que fuerzan a su incumplimiento. (4) Es necesario superar la teoría liberal de los derechos que se construye sobre la noción de propiedad privada y la concepción de individualidad de los derechos hacia una teoría social que parta del discurso participativo y plural de los derechos que aseguren su efectividad. (5) El reforzamiento de los mecanismos judiciales para asegurar la protección y garantía de este derecho incluye la toma de cierta conciencia moral y activismo político desde la sociedad.

39. Ibíd., 45-8. 
En definitiva, es necesario recuperar la conciencia jurídico-política sobre estos derechos a través de una dogmática constitucional que reoriente el control de razonabilidad y su proporcionalidad hacia la profundización democrática y garantista de los principios y valores sociales.

\section{CONCLUSIONES}

La exigibilidad judicial de los derechos sociales, y en concreto de la jubilación, por parte del Estado debe propiciar lecturas progresivas de los derechos en las cuales se determinen los avances de protección tanto en la norma jurídica como en el manejo de las políticas públicas. En este sentido es necesario entender el valor axiológico que tienen los derechos sociales de acuerdo con lo que señala el artículo 11 de la Constitución, y en concreto el previsional de jubilación, como fundamento para la satisfacción de las necesidades básicas y goce de su libertad de los grupos de atención prioritarias, en especial con doble o múltiple vulnerabilidad.

Sin embargo, la evaluación de la protección que ofrece un ordenamiento jurídico resulta menos compleja que la explicación de las políticas públicas por parte del juzgador, pues no siempre están bien identificados los remedios adecuados en su diseño.

El contenido esencial del derecho a la seguridad social se respalda en la satisfacción mínima y oportuna de ciertas condiciones para el mejoramiento de la calidad de vida y dignidad de las personas. Por ello, las distintas funciones del Estado deben impulsar dicha protección en sus respectivas esferas por medio de deliberaciones democráticas más garantistas que incluyan a los beneficiarios en la administración del sistema. A ello se agrega el análisis sobre temporalidad, modalidades y alcance universal del sistema previsional desde una perspectiva más progresiva que priorice la inclusión social y económica.

El reconocimiento efectivo de la jubilación exige una ardua labor de concientización, reconocimiento, planificación, gestión y regulación concreta de las relaciones laborales de los poderes de turno desde una lógica alternativa garantista y no de justificación del estatismo estatal; lo contrario conlleva a interpretaciones simuladas y oportunistas que, lejos de aplicar de forma adecuada el principio in dubio pro justitia sociales, solo refrendan el statu quo. En este sentido, la argumentación jurídica debe contribuir a dicho fin a través de la armonización concreta de los principios y valores que favorezcan lecturas progresivas y no regresivas de estos derechos.

Resulta difícil en la práctica asimilar en igual proporción a los derechos civiles y políticos de los sociales pues, pese a los esfuerzos constitucionales por establecer la interconectividad, complementariedad e igual jerarquía, existe la necesidad de eva- 
luaciones en los costes y los avances internacionales todavía hacen estas distinciones. Ello lo evidencia el análisis de la sentencia de los cinco pensionistas.

Las interpretaciones de las lecturas relacionadas con derechos sociales —en este caso, la previsional, relacionada con la jubilación universal - supone una lectura hermenéutica pro derechos sociales con el fin de alcanzar el bienestar de las personas que aseguren su dignidad. Las lecturas restrictivas de derechos sociales se muestran contrarias al objetivo preeminente del bienestar general, establecido en la Constitución. Por ello, se someten a un escrutinio estricto en términos de análisis de la razonabilidad de la medida o norma que pretenda limitar la extensión del derecho. En este sentido, los juzgadores "activistas" deben convertirse en verdaderos modeladores de las democracias en crisis y bancarrota.

La interpretación y aplicación de los derechos sociales requieren el desarrollo de una teoría de la razonabilidad que rompa con el pensamiento parcial, fragmentario y único formal-lógicamente válido, imperante en nuestras realidades, hacia la búsqueda de alternativas contextualizadas y reales a nuestros sistemas político-jurídicos diversos en donde asume un rol fundamental el discurso práctico axiológico. Esta liberación de la razón — que incluye la capacidad comunicativa y cognitiva — invita a pensar la ciencia del derecho desde el conflicto con un espíritu de autoconciencia crítica de la sociedad.

\section{BIBLIOGRAFÍA}

Aldao, Martín, y Laura Clérico. "Los derechos previsionales y la seguridad social”. En La Constitución en 2020. 48 propuestas para una sociedad igualitaria, coordinado por Roberto Gargarella, 171-7. Buenos Aires: Siglo XXI, 2011.

Alexy, Robert. Derechos sociales y ponderación, 2. ${ }^{\mathrm{a}}$ ed. Madrid: Fundación Coloquio Jurídico Europeo, 2009.

- Teoría de los derechos fundamentales. Traducción y Estudio Introductorio de Carlos Bernal Pulido, 2. ${ }^{a}$ ed. en español. Madrid: Centro de Estudios Constitucionales, 2008.

Arango, Rodolfo. El concepto de derechos sociales fundamentales. Bogotá: Legis, 2005.

Argentina. Corte Suprema. Caso Víctor Francisco Rolán Zapa. 30 de octubre de 1986.

Bernal Pulido, Carlos. El Derecho de los derechos. Bogotá: Universidad Externado de Colombia, 2005.

Capella, Juan Ramón. Elementos de análisis jurídico. Madrid: Trotta, 2002.

Cárcova, Carlos María. Derecho, Política y Magistratura. Buenos Aires: Biblos, 1996.

Cárdenas, David. "El principio de no regresividad en el derecho a la seguridad social: caso suspensión y reducción de pensiones jubilares del Banco Central del Ecuador". Tesis de maestría, UASB-E, 2018. 
Corte IDH. "Sentencia de 28 de febrero de 2003 (Fondo, Reparaciones y Costas)". Caso Cinco Pensionistas vs. Perú. 28 de febrero de 2003. https://bit.ly/3iIXM5J.

—. "Sentencia de 24 de noviembre de 2006 (Excepciones Preliminares, Fondo, Reparaciones y Costas)". Caso Trabajadores Cesados del Congreso (Aguado Alfaro y otros) vs. Perú. 24 de noviembre de 2006. https://bit.ly/31YrT39.

Courtis, Christian. "La prohibición de regresividad en materia de derechos sociales: apuntes introductorios". En Ni un paso atrás: la prohibición de regresividad en materia de derechos sociales, compilado por Christian Courtis. Buenos Aires: Del Puerto, 2006.

Chávez, Mario. "El derecho a percibir pensión y remuneración en el marco de la Constitución". Palestra del Tribunal Constitucional. Revista de Doctrina y Jurisprudencia, vol. XXXV, n. ${ }^{\circ} 11$ (2008): 129-46.

De Cabo Martín, Carlos. Pensamiento crítico, constitucionalismo crítico. Madrid: Trotta, 2014.

De la Cueva. El nuevo derecho mexicano del trabajo, vol. 1. Ciudad de México: Porrúa, 2007.

Dugit, León. Manual de Derecho Constitucional. Granada: Comares, 2005.

Ecuador. Constitución de la República del Ecuador. Registro Oficial 449, 20 de octubre de 2008.

Esquirol L., Jorge, Las ficciones del derecho latinoamericano. Bogotá: Siglo del Hombre / Universidad de los Andes, 2014.

Ferrajoli, Luigi. Derechos y garantías. La ley del más débil, 3. a ed. Madrid: Trotta, 2002.

Haberle, Peter. Pluralismo y Constitución. Estudios de teoría constitucional de la sociedad abierta. Madrid: Tecnos, 2002.

Gargarella, Roberto, comp. La Constitución en 2020: 48 propuestas para una sociedad igualitaria. Buenos Aires: Siglo XXI, 2011.

Guastini, Ricardo. Teoría e ideología de la interpretación constitucional. Madrid: s.e., 2008.

Holmes, Stephen, y Cass R. Sunstein. El costo de los derechos. Por qué la libertad depende de los impuestos. Buenos Aires: Siglo XXI, 2005.

Maurino, Gustavo. "El artículo 28. Hacia una república basada en razones", en La Constitución en 2020. 48 propuestas para una sociedad igualitaria, coordinado por Roberto Gargarella. Buenos Aires: Siglo XXI, 2011.

Médici, Alejandro. La Constitución Horizontal. Teoría constitucional y giro decolonial. Aguascalientes, San Luis de Potosí, S. Cristóbal de las Casas: MISPAT y otros, 2012.

Navas, Marco. "Claves metodológicas para la investigación del nuevo constitucionalismo latinoamericano. Una mirada socio jurídica". Revista Culturas Jurídicas 4, n. 9 (2017). Accedido 29 de marzo de 2020.

Noguera-Fernández, Albert. Los derechos sociales en las nuevas constituciones latinoamericanas. Valencia: Tirant lo Blanch, 2010.

ONU. Asamblea General. Convención Americana sobre Derechos Humanos o Pacto de San José. 22 de noviembre de 1969. 
-. Asamblea General. Pacto Internacional de Derechos Económicos, Sociales y Culturales. Adoptado por resolución 2200 (XXI). 16 de diciembre de 1966.

ONU. OIT. Convenio 40 sobre la conservación de los derechos de pensión en los migrantes. 1935.

—. C128. Convenio sobre las prestaciones de invalidez, vejez y sobrevivientes. 1967.

Pautassi, Laura. Legislación previsional y equidad de género en América Latina. Santiago de Chile: CEPAL-ECLAC, 2002.

Pisarello, Gerardo. Los derechos sociales y sus garantías. Elementos para una reconstrucción. Madrid: Trotta, 2007.

Pizzolo, Calogero. Globalización e integración. Ensayo de una teoría general. Buenos Aires: Ediar, 2002.

Prieto Sanchís, Luis. Justicia Constitucional y derechos fundamentales, 2. ' ed. Madrid: Trotta, 2009.

Rodríguez Garavito, César. "El activismo dialógico y el impacto de los fallos sobre los derechos sociales". En Por una justicia dialógica. El poder judicial como promotor de la deliberación democrática, compilado por Roberto Gargarella. Buenos Aires: Siglo XXI, 2014.

Storini, Claudia. ¿"Sobre quién reposa la tortuga? A vueltas con los límites de la interpretación constitucional”. En Perspectivas Constitucionales. Quito: Corporación de Estudios y Publicaciones, 2010.

Tushnet, Mark. ¿Por qué la Constitución importa? Bogotá: Universidad Externado de Colombia, 2012.

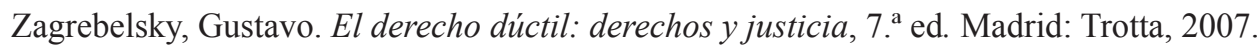

